\title{
KNOWLEDGE, ATTITUDE AND PRACTICE REGARDING IMMUNIZATION AMONG MEDICAL STUDENTS
}

\author{
Rubina Shrestha, ${ }^{1}$ Pradip Chhettri, ${ }^{1}$ Chet Kant Bhusal, ${ }^{1}$ Rajendra Ruchal, ${ }^{1}$ Saneep Shrestha, ${ }^{1}$ Bipan Shrestha ${ }^{2}$
}

\begin{abstract}
INTRODUCTION

Prevention of disease is the necessity of today's life. Immunization is the most important component of preventive medicine. Knowledge and attitude of health professionals have significant role in increasing the acceptance of immunization. This study is aimed to determine the association between knowledge and attitude towards immunization and its practice among medical students and emphasis on the need of immunization education intervention among medical students.
\end{abstract}

\section{MATERIAL AND METHODS}

Institutional based cross-sectional study among 397 medical students studying Bachelor in Medicine and Bachelor in Surgery (MBBS) was conducted in Universal College of Medical Sciences, Bhairahawa, Nepal. Purposively $1^{\text {st }}$ to $4^{\text {th }}$ year medical students were selected.

\section{RESULTS}

Among 397 students, 59\% had good knowledge regarding immunization, 63\% had positive attitude and 47\% had applied the knowledge and attitude in practice. Level of knowledge, attitude as well as practice regarding immunization was found statistically significant among medical students with their year of study. The analysis found that level of knowledge was more with $4^{\text {th }}$ year students $89.47 \pm 7.92$ and least with $1^{\text {st }}$ year students $62.82 \pm 13.01$. Third year and $4^{\text {th }}$ year students had good attitude with mean score of $85.66 \pm 9.13$ and $85.49 \pm 9.51$ respectively. Similarly, practice level was found more among $3^{\text {rd }}$ and $4^{\text {th }}$ year student, while least among 1 st year students $39.89 \pm 21.16$. There is statistically weekly positive correlation between knowledge, attitude and practice in overall among the medical students.

\section{CONCLUSION}

The acceptance of immunization can be increased by increasing the level of knowledge and attitude regarding immunization thus providing a foundation to include a comprehensive immunization education to medical students.

KEY WORDS Health professionals, immunization, medical students

1. Department of Community Medicine, Universal College of Medical Sciences, Bhairahawa, Nepal

2. Department of Orthopedics, Universal College of Medical Sciences, Bhairahawa, Nepal

DOI: https://doi.org/10.3126/jucms.v7i1.24692

\author{
For Correspondence \\ Dr. Rubina Shrestha \\ Department of Community Medicine \\ Universal College of Medical Sciences \\ Bhairahawa, Nepal \\ E-Mail: rubinashrestha82@gmail.com
}




\section{INTRODUCTION}

Immunization is the process of administration of antigen in the form of vaccine to make an individual immune against an infectious disease. After the vaccine is administered, it helps to stimulate body's own immune system such that it protects an individual from an infectious disease. ${ }^{1}$ It is well known tool used for the purpose of control and elimination of life threatening infectious disease. It is estimated that it prevents 2 to 3 million deaths each year and additional 1.5 million deaths could be avoided with the improvement in global vaccination coverage. ${ }^{2}$ World Health Organization (WHO) initiated expanded program on Immunization (EPI) in 1974 through a resolution passed at World Health Assembly (resolution WHA 27.57). The aim of initiation of EPI was to eradicate small pox and also had target against six infectious diseases ( tuberculosis, poliomyelitis, diphtheria, pertussis, tetanus and measles). Following massive vaccination campaigns conducted by WHO for the eradication of small pox from 1967 to 1977 eradication was achieved on $9^{\text {th }}$ December $1979 .{ }^{1}$ In year 2016, death among children under the age of 5 years was found to be 5.6 million out of which there were 1500 underfive deaths per day and 2.6 million deaths in the first month of life globally. More than half of these early child deaths were due to conditions that could be prevented with access to simple, affordable interventions like vaccination. Global vaccination coverage has stuck at $86 \%$ with no significant changes during the past year.

Nepal is a developing country with under- 5 mortality rate 39 deaths per 1,000 live births, infant mortality rate 32 deaths per 1000 live births, and neonatal mortality 21 deaths per 1,000 live birth. ${ }^{4}$ Though Nepal met its millennium development goal (MDG) target of reducing under-5 mortality, it has a long way to go to meet the SDG target for 2017 , reducing under 5 mortality to 28 death per 1,000 live births. ${ }^{5}$ Nepal Launched expanded program on immunization in 2034 BS (1977/1978) and is a priority 1 program of Government of Nepal. It has successfully played a great role in Nepal's achievement of MDG 4 and 5 by reducing morbidity \& mortality among children and mothers from vaccine preventable diseases. Eleven antigens are provided through the national immunization program to eligible infants and children through more than 1600 outreach sessions. The highest coverage recorded was of BCG (87\%), DPT-HepB-Hib3 $(81 \%)$, and oral polio vaccine $3(79 \%)$. ${ }^{6}$ Nepal is polio free since 2010 and was awarded as polio free country on $27^{\text {th }}$ march 2014. The burden of diseases like Japanese encephalitis and measles/rubella has also been successfully reduced.

Medical colleges in Nepal under Tribhuwan University accommodate students for 5 year to complete MBBS course. In this 5 year since 1 st year of the course in Community Medicine department, students come across community as well as patients where they need to interact with the people regarding immunization, its availability and its benefits. Their involvement in the community through the field work and interactions with patients in their clinical years, itself makes them one of the important sources to provide health awareness regarding immunization. Immunization knowledge and attitudes of student's especially medical students can play a possible important contributor role in future public health campaigns.

Very limited research has been conducted to identify the level of knowledge, attitudes and practice of medical students in Nepal. Thus, this study aims to identify the association between knowledge and attitude towards immunization and its practice among medical students in relation to recommend vaccination thus contributing to the immunization program one of the priority program of Nepal government.

\section{MATERIAL AND METHODS}

An institutional based cross sectional study was conducted using complete enumeration method with self-administered questionnaire. Questionnaire was prepared by conceptualizing the different similar international studies, concept and components in Nepalese context and National Immunization Guidelines of Nepal. ${ }^{8-11}$ The questionnaire was pretested to ensure the validity of the instruments and used among the medical students of $1^{\text {st }}$ to $4^{\text {th }}$ year, at Universal College of Medical Sciences. Those students who were absent on the day of data collection were excluded from the study. Data collection was done by distributing the prepared questionnaire to all the MBBS students of $1^{\text {st }}$ to $4^{\text {th }}$ year during lunch hour at the end of their academic year. Maximum 30 minutes time was given to complete the questionnaire without using any supplemental aids.

Questions related to knowledge regarding Immunization included options in yes or no for each question. Each correct answer was given score 1 and incorrect answer score 0 . Questions related to attitude towards Immunization included options in agree, neutral and disagree with the given statement and was measured by using likert scale ranging from agrees to disagree. ${ }^{12}$ We scored positive questions as: 2 for agree, 1 for neutral and 0 for disagree similarly for negative questions as 2 for disagree, 1 for neutral and 0 for agree. The result of the scale was measured as having favourable attitude and unfavourable attitude towards immunization. Question related to practice regarding immunization was also measured, where score 1 was given for "yes" and 0 for "no". Scores of each component (knowledge, attitude and practice) were made equal weighted, dividing obtained score of each respondents by total score of each component and multiplied by 100 .

\section{Data analysis}

Data were analysed using IBM SPSS Version 20.0. Descriptive statistics using mean, median, standard deviation, percentage, minimum and maximum values were calculated. ANOVA test was done to show the statistical significant in 
knowledge, attitude and practice level among different year of MBBS student. Correlation was done to find the relation between knowledge, attitude and practice score. Two-sided test was used for all statistical analyses and considered pvalues less than 0.05 as statistically significant.

\section{RESULTS}

In the study total 397 questionnaire were completed by MBBS students of different year from $1^{\text {st }}$ year to $4^{\text {th }}$ year. Mean knowledge score was $80.32 \pm 13.82$, median score 83.33 with the range of 66.67. We took the median score as cutoff score to separate poor knowledge and good knowledge. $58.9 \%$ of students had good knowledge regarding immunization. Most of the students had positive attitude $(63 \%)$ followed by neutral attitude (34\%) and having negative attitude (3\%). Mean score was $84.03 \pm 9.26$ with the range of 50 . We separated the different components of attitude by dividing the range (50) into 3 equal parts as positive attitude (84-100), neutral (67-83) and negative attitude (50-66). While analysing the practice regarding immunization on regular basis of counselling to encourage general population for immunization it was found that $47.9 \%$ had good practice while $52.1 \%$ were not confident enough and the main reason were not having full knowledge regarding immunization to explain all the benefits and side effects and this group mainly included $1^{\text {st }}$ year and $2^{\text {nd }}$ year students.

On comparison between groups and within the groups ANOVA test was applied to compare the statistical significant between the knowledge, attitude and practice level among different year of MBBS students. It shows that students having more knowledge and good attitude toward immunization had implemented the received knowledge to practice. $4^{\text {th }}$ year students had more knowledge whereas $1^{\text {st }}$ year had less knowledge having level of practice more among $4^{\text {th }}$ year students in comparison to $1^{\text {st }}$ year students (Table 1). To strengthen this analysis the correlation between knowledge, attitude and practice was found to be statically weakly positive (table 2).

Table 1. Comparison of knowledge, attitude and practice level among different year of MBBS students

\begin{tabular}{|c|c|c|c|c|c|c|}
\hline & Year & $\mathbf{N}$ & Mean & $\begin{array}{l}\text { Std. } \\
\text { Deviation }\end{array}$ & F- Value & P-Value \\
\hline \multirow{5}{*}{ Knowledge Score } & $1^{\text {st }}$ year & 94 & 62.82 & 13.01 & \multirow{5}{*}{146.6} & \multirow{5}{*}{$<0.001$} \\
\hline & $2^{\text {nd }}$ year & 108 & 83.95 & 8.77 & & \\
\hline & 3 Year & 90 & 83.58 & 7.62 & & \\
\hline & $4^{\text {th }}$ Year & 105 & 89.47 & 7.92 & & \\
\hline & Total & 397 & 80.32 & 13.82 & & \\
\hline \multirow{5}{*}{ Attitude Score } & $1^{\text {st }}$ year & 94 & 80.99 & 9.27 & \multirow{5}{*}{5.40} & \multirow{5}{*}{$<0.001$} \\
\hline & $2^{\text {nd }}$ year & 108 & 83.91 & 8.37 & & \\
\hline & $3^{\text {rd year }}$ & 90 & 85.66 & 9.13 & & \\
\hline & $4^{\text {th }}$ year & 105 & 85.49 & 9.51 & & \\
\hline & Total & 397 & 84.03 & 9.22 & & \\
\hline \multirow{4}{*}{ Practice Score } & $\begin{array}{l}1^{\text {st }} \text { year } \\
2^{\text {nd }} \text { year }\end{array}$ & $\begin{array}{l}94 \\
108\end{array}$ & $\begin{array}{l}39.89 \\
62.50\end{array}$ & $\begin{array}{l}21.16 \\
22.01\end{array}$ & \multirow{4}{*}{33.563} & \multirow{4}{*}{$<0.001$} \\
\hline & $3^{\text {rd }}$ year & 90 & 67.22 & 18.97 & & \\
\hline & $4^{\text {th }}$ year & 105 & 64.29 & 21.61 & & \\
\hline & Total & 397 & 58.69 & 23.50 & & \\
\hline
\end{tabular}

Table 2. Correlation between knowledge, attitude and practice regarding immunization $(\mathrm{N}=397)$

\begin{tabular}{|c|c|c|c|c|}
\hline & & $\begin{array}{l}\text { Knowledge } \\
\text { score }\end{array}$ & Attitude score & Practice Score \\
\hline \multirow{6}{*}{$\begin{array}{l}\text { Knowledge } \\
\text { score } \\
\text { Attitude } \\
\text { Score }\end{array}$} & Pearson Correlation & 1 & $0.251 * *$ & $0.369^{* *}$ \\
\hline & Coefficient & & & \\
\hline & Sig. (2-tailed) & & $<0.001$ & $<0.001$ \\
\hline & Pearson Correlation & $0.251 * *$ & 1 & $0.147^{* *}$ \\
\hline & Coefficient & & & \\
\hline & Sig. (2-tailed) & $<0.001$ & & 0.003 \\
\hline \multirow{3}{*}{$\begin{array}{l}\text { Practice } \\
\text { Score }\end{array}$} & Pearson Correlation & $0.369 * *$ & $0.147 * *$ & 1 \\
\hline & Coefficient & & & \\
\hline & Sig. (2-tailed) & $<0.001$ & 0.003 & \\
\hline
\end{tabular}

** Correlation is significant at the 0.01 level (2-tailed)

\section{DISCUSSION}

Disease prevention has an important role as the morbidity and mortality caused and the cost needed to treat them requires all of us to focus more towards their prevention. Immunization is one of the most successful component of preventive medicine. 13 This study revealed several important findings on knowledge, attitude and practice regarding immunization. The finding of this study revealed that Increase in knowledge was seen more among $3^{\text {rd }}$ and $4^{\text {th }}$ year students in comparison to $1^{\text {st }}$ and $2^{\text {nd }}$ year students. Students who reported experience delivering vaccines had significantly better knowledge and felt more confident in their ability to respond to patient/parent concerns regarding immunization then those without experience. This finding corresponds to the theory of planned behaviour that Physician with better knowledge, positive attitude and beliefs would make health care professionals more successful in immunization promotion, further says that an individual behaviour is shaped by their attitude, subjective norms and perceived control. It is presumed that positive attitude of medical students towards vaccination would lead to increased uptake of immunization. ${ }^{14}$ This finding is also supported by the study conducted by Smailbegovic at al who found lack of knowledge in physicians about the efficacy as well as patient eligibility for vaccine can influence the decision about getting vaccination. ${ }^{15}$ Strong correlation between physicians' knowledge about vaccination and their recommendation to their patients was also seen in some studies. ${ }^{16,17}$ Furthermore studies suggested that having knowledge about the immunization among health care professionals helps to convince people to get vaccinated which can subsequently improve the efficiency of government program $^{18,19}$ supporting this study.

Majority of group who said that they are not confident enough in addressing patient/parent concerns regarding immunization the reason being was because of level of knowledge they have and the lack of opportunities for all students to deliver vaccines while in medical school. This group included more number of students from $1^{\text {st }}$ year and $2^{\text {nd }}$ year MBBS. It is, therefore important that providers are aware of immunization guidelines and are able to communicate the received information to patients and parents. In previous studies as 
well, physicians reported discomfort discussing misconceptions about adverse events following immunization with patients and many admitted to not being sure about the relationship between vaccines and chronic diseases. ${ }^{20,21}$ This suggests that the discomfort with immunization is an issue that is relevant at both a trainee and practicing level. Studies have shown role of variety of factors associated in increase in uptake of immunization like role of media- TV, newspapers, radio, and internet along with this health workers including doctors, nurse and FCHV have been recognized as a key channel for interpersonal health communication. ${ }^{22}$ Working through professional societies may provide opportunities to incorporate immunization training into professional development standards and to communicate vaccination policies. Minimizing missed opportunities \& barriers to vaccination in both public \& private health sectors can help to improve immunization coverage to meet development goals.

Majority of students reported positive attitudes and supportive practice towards immunization from the assessment of attitude towards immunization. Vaccination knowledge and attitudes of student's especially medical students play a possible important contributor role in future public health campaigns. A strong association found between vaccine knowledge and attitudes implies recommendations to introduce a specialized vaccination curriculum at both the undergraduate and graduate level of medical study. ${ }^{24}$ Similar to this study, study done by Prislin et al. and Donald Mastuda suggested that a diversity of factors influence the immunization of children where parents beliefs, attitudes and perception of immunization plays the most important role in getting their children vaccinated. ${ }^{25}$ Similarly from the study conducted in students in Paris, France and surrounding region concluded that the knowledge regarding vaccination among general practioner who interacts with these young individuals in addition to mass media information had an essential role in vaccine uptake. $^{8}$

However our study had some limitations. It was restricted to the students from Universal College of Medical Sciences only; thus having a relatively small population of medical students. Immunization related content in most medical schools is scattered throughout the curriculum with little apparent communication, making the review challenging. This study could be enlarged including students from other medical colleges, to compare the results making it more helpful.

\section{CONCLUSION}

The study reveals the level of knowledge of medical students' according to the year of their education and the influence of students' knowledge, experience and confidence on delivering immunization. This study provides an important base to support the development of educational interventions related to immunization, efforts to standardize immunization training for medical students as part of their curriculum for each year of MBBS students such that the level of knowledge and students confidence about immunization can be increased.

\section{ACKNOWLEDGEMENTS}

We acknowledge institutional review board of Universal College of medical sciences for the ethical approval of this study. We also acknowledge all the Medical Student of Universal College of Medical Sciences for providing valuable time and information for this study.

\section{REFERENCES}

1. WHO Expanded program on Immunization http://www. who.int /topics/immunization/en/

2. WHO fact sheet updated $2017 \mathrm{http} / / / \mathrm{www}$. who.int/mediacentre /factsheets/fs378/en/

3. WHO fact sheet updated 2018 https://www.who.int/en/newsroom/fact-sheets/detail/immunization-coverage.

4. ERA/Nepal and ICF, "Nepal Demographic and Health Survey 2016," MOH/Nepal, New ERA/Nepal, and ICF, Kathmandu, Nepal, 2017.

5. National Planning Commission, 2015: Sustainable Development Goals, 2016-2030. National (Preliminary) Report, Government of Nepal. http://www.undp.org/content /dam/nepal/docs/reports/SDG\%20final\%20report-nepal.

6. Annual Report. Department of Health Services.2072/73 (2015/2016) . Government of Nepal, Ministry of Health. http: // dohs .gov.np/wp content/uploads/2017/06/DoHS_Annual_ Report_2072_73.

7. Annual Report. Department of Health Services.2071/72 (2014/2015). Government of Nepal, Ministry of Health. http://doh s.gov.np/wp content/uploads/2016/06/DoHS Annual_Report_2071_72.

8. Mellon G, Rigal L, Partouche H, Aoun O, Jaury P, Joannard N, et al. Vaccine knowledge in students in Paris, France, and surrounding regions. Canadian Journal of Infectious Diseases and Medical Microbiology. 2014;25(3):141-6.

9. Barera D, Thompson K. Medical Student knowledge, attitudes, and practices regarding immunization. J Vaccines Vaccin. 2015 ;6:268.

10. Pelly LP, PierrynowskiMacdougall DM, Halperin BA, Strang RA, Bowles SK, Baxendale DM, et al. THE VAXED PROJECT: an assessment of immunization education in Canadian health professional programs. BMC Med Educ. 2010; 10(86):14726920.

11. Arede M, Bravo-Araya M, Bouchard É, Gill GS, Plajer V, Shehraj A, et al. Combating Vaccine Hesitancy: Teaching the Next Generation to Navigate Through the Post Truth Era. Frontiers in public health. 2018; 6 . 
12. Likert R. A technique for the measurement of attitudes. Archives of psychology.1932; 140: 155.(18).

13. Edwards KM. State mandates and childhood immunization: JAMA. 2000 Dec 27;284(24):3171-3.

14. Ajzen I. The theory of planned behavior. Organizational behavior and human decision processes. 1991;50(2):179-211.

15. Smailbegovic MS, Laing GJ, Bedford H. Why do parents decide against immunization? The effect of health beliefs and health professionals. Child: care, health and development. 2003; 29(4):303-11.

16. Pearson ML, Bridges CB, Harper SA. Influenza vaccination of health-care personnel. CDC, Mortality and Morbidity Weekly Report. 2006 Feb; 55:1-6.

17. Pickering LK, Baker CJ, Freed GL, Gall SA, Grogg SE, Poland GA, Rodewald LE, Schaffner W, Stinchfield P, Tan L, Zimmerman RK. Immunization programs for infants, children, adolescents, and adults: clinical practice guidelines by the Infectious Diseases Society of America. Clinical Infectious Diseases. 2009 Sep 15; 49(6):817-40.

18. Abramson $\mathrm{ZH}$, Levi O. Influenza vaccination among primary healthcare workers. Vaccine. 2008;26(20):2482-9.

19. Müller D, Szucs TD. Influenza vaccination coverage rates in 5 European countries: a population-based cross-sectional analysis of the seasons 02/03, 03/04 and 04/05. Infection. 2007 Oct 1 ;35(5):308-19.

20. Jelleyman T, Ure A. Attitudes to Immunisation: a survey of health professionals in the Rotorua District. This Issue of the Journal. 2004; 117(1189):1.

21. Petousis-Harris H, Goodyear-Smith F, Turner N, Soe B. Family physician perspectives on barriers to childhood immunisation. Vaccine. 2004;22(17-18):2340-4.

22. Devkota S, Simkhada P, van Teijlingen E, Rai LD. Parents Knowledge and Practices to Childhood Immunization in Nepal: Implications for Health Policy. Health Science Journal. 2013; 7(4):370.

23. Olorunsaiye CZ, Langhamer MS, Wallace AS, Watkins ML. Missed opportunities and barriers for vaccination: a descriptive analysis of private and public health facilities in four African countries. The Pan African medical journal. 2017; 27(Suppl3).

24. Cvjetkovic SJ, Jeremic VL, Tiosavljevic DV. Knowledge and attitudes toward vaccination: a survey of Serbian students. Journal of infection and public health. 2017; 10(5):649-56.

25. Prislin R, Dyer JA, Blakely CH, Johnson CD. Immunization status and sociodemographic characteristics: the mediating role of beliefs, attitudes, and perceived control. American Journal of Public Health. 1998 Dec; 88(12):1821-6. 